International Journal of Electrical Engineering and Technology (IJEET)

Volume 11, Issue 4, June 2020, pp. 266-274, Article ID: IJEET_11_04_030

Available online at https://iaeme.com/Home/issue/IJEET? Volume $=11 \&$ Issue $=4$

ISSN Print: 0976-6545 and ISSN Online: 0976-6553

DOI: https://doi.org/10.34218/IJEET.11.4.2020.030

\title{
MLI TECHNIQUE FOR PLACEMENT AND SIZING OF DG FOR MINIMUM LINE LOSSES
}

\author{
G Sasi Kumar \\ Associate Professor, Electrical and Electronics Engineering, \\ VNRVJIET - Vallurupalli Nageswara Rao Vignana Jyothi Institute of Engineering \& \\ Technology, Hyderabad, Telangana, India. \\ S Sarat Kumar \\ Professor, Electrical and Electronics Engineering, \\ MVGRCE - Maharaj Vijayaram Gajapathi Raj College of Engineering, \\ Vizianagaram, Andhra Pradesh, India.

\section{S V Jayaram Kumar} \\ Professor, Electrical and Electronics Engineering, \\ JNTUH - Jawaharlal Nehru Technological University, Hyderabad, Telangana, India.
}

\begin{abstract}
In distribution system, as shoot up requisition of distributed generations (DGs) has alter its custom from passive to active. Distributed generation can be desegregated into distribution systems to encounter the growing load demand. This paper suggests Maximum Loadability Index (MLI) technique for the optimal location and sizing of $D G$. The benefit of suggested technique is applied for single DG location and assessment on 6bus and IEEE 33-bus radial distribution systems. Load flow algorithm is applied for power flow calculations with abiding power load. Diminish of real power and reactive power, maximal of voltage profile and loadability of assessment system are reviewed as staging parameters. The benefit of the suggested technique is differentiate with subsist technique, the outcome exhibit that the suggested technique is worthwhile.
\end{abstract}

Key words: Distributed Generation, Placement, Maximum Loadability Index, Voltage Profile..

Cite this Article: G Sasi Kumar, S Sarat Kumar and S V Jayaram Kumar, MLI Technique for Placement and Sizing of DG for Minimum Line Losses. International Journal of Electrical Engineering and Technology, 11(4), 2020, pp. 266-274.

https://iaeme.com/Home/issue/IJEET?Volume $=11 \&$ Issue $=4$ 


\section{INTRODUCTION}

Today the In present days, the involvement of distributed generation is increasing. This increased distributed generation causes over voltages problem in distribution system. In order to avoid this proper placing of DG and sizing of DG is very important. In [1], DG was used just for the reduction of power system losses. In this paper the location of distributed generation is based on the reduction of power losses. Wang et al., proposed an analytical approach for the placement of distributed generation. In this paper DG is optimally located on radial distributed system based on analytical approach [2].

Rahman et al., proposed a new method for the placement of embedded generators, in addition to placement the sizing of DG also evaluated using this new method [3]. Nadri proposed dynamic approach for the planning of distributed system in the presence of distributed generation [4]. Here, system planning is done considering the distributed generation and its effects are explained. Acharya et al., proposed a new analytical approach, In which the optimal allocation of DG in primary distribution network is through this approach 5].

Alsaadi and Gholami was proposed an effective approach for distribution system, in this paper a new power flow solution method was proposed in the presence of distributed generation [6]. In [7], Backward/Forward sweep algorithm was proposed for power flow calculation in radial distribution systems. Different authors proposed different methods like sensitivity analysis, V-Index, analytical approach and numerous optimization techniques for optimal location and sizing of DG's [8-9]. In the contemporary condition, evolutionary programming is used for the optimal location and sizing of DG's. Genetic algorithm, particle swarm optimization, Tabu search, artificial immune system and many other evolutionary programs were proposed by different authors for optimal allocation of DG's [10-11]. All these methods were incompetent to guarantee the solution, because attain solution may be local optimal or global optimal.

This paper implements a new method for placement of DG and sizing based on the line maximum loadability index. Earlier Model analysis and continuous power flow method are used for obtaining the most critical bus in the distribution network which could lead to instability of the system when the loads are increased. The new method is also identified the critical bus for the DG placement. The sizing of DG is estimated considering the minimum losses by using search algorithm. Finally finding the placement and sizing of DG using the new method is simpler and requires less time as compared with existing algorithms.

The sections of this paper are organized as follows : in Section 2, Mathematical modeling of Maximum Loadability Index of a equivalent of electrical distribution line(suppose $\mathrm{k}-\mathrm{m}$ line).Section 3 presents implementation of algorithm based on MLI. Effectiveness of proposed algorithm tested on IEEE -6 bus and IEEE - 33 bus RDS test system presented in Section 4. The results are discussed in detail and compared with existing algorithm.

\section{MATHEMATICAL MODELING OF MAXIMUM LOADABILITY INDEX}

Fig. 1 shows the equivalent circuit of a simple line with sending and receiving ends.

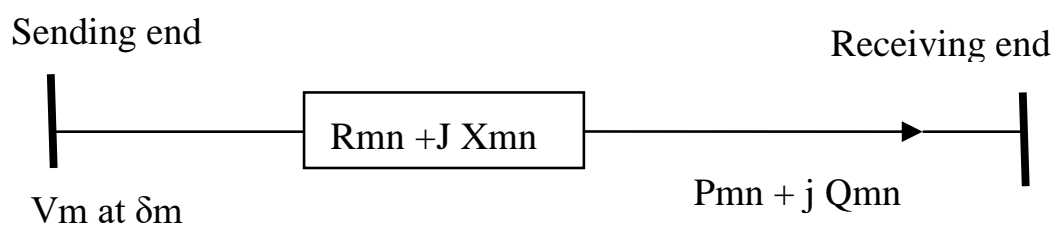

$\mathrm{Vn}$ at $\delta \mathrm{n}$

Figure 1 Equivalent line of electric distribution network. 
The formulation of multi objective function (MOF) consists of two terms, first one is the power loss and second one is switching operations.

Equation 1 represents the expression for the calculation of maximum loadability index (MLI) [12] .

$$
\text { MLI }=\frac{V_{m}^{2}\left[-\left(r_{m n} P_{m n}+x_{i j} Q_{i j}\right)+\sqrt{\left(r_{m n}^{2}+x_{m n}^{2}\right)\left(P_{m n}^{2}+Q_{m n}^{2}\right)} \mid\right.}{2\left(x_{i j} P_{m n}-r_{m n} Q_{m n}\right) *\left(x_{i j} P_{m n}-r_{m n} Q_{m n}\right)}
$$

Where $\mathrm{R} \& \mathrm{X}$ indicates resistance and reactance of the line, $\mathrm{V} \& \delta$ indicates voltage magnitude and angles at nodes respectively, $\mathrm{P} \& \mathrm{Q}$ are the real and reactive powers of the line respectively. Suffixes ' $m$ ' and ' $n$ ' are the sending end node and receiving end nodes respectively.

\section{PROPOSED METHOD (MAXIMUM LOADABILITY INDEX METHOD)}

The following steps are used for the implementation of proposed method:

Step 1: Read the system data

Step 2: Run Backward/forward algorithm and calculate power flows and voltages

Step 3: from step 2, determine MLI for all the lines in the system using Equation 1

Step 4: Identify the line which is having minimum Loadability index

Step 5: set the optimal Location of DG as the ending bus of the line which is having minimum MLI

Step 6: Set DG output to zero initially

Step 7: Check the DG real power Constraints, if satisfied then go to next step otherwise go to step 11

Step 8: Run Backward/forward algorithm and calculate power flows and voltages with DG

Step 9: Save $X_{\text {iter }}$ for each DG real power

Step 10: if $X_{\text {iter }}$ is less than or equal to $X_{\text {iter-1 }} 1$ then go to step 14 otherwise step 12

Step 11: DG values are taken from the constraints

Step 12: DG values set as optimum

Step 13: check voltage limits, if satisfied go to step 16 otherwise go to step 14

Step 13: find the DG real power based on voltage condition and then go to step

Step 14: update real power of DG and then repeat steps 7, 8 and 9

Step 15: determine the error using the following formula: error=step11-step13-step 9 and neglect unsuitable vales go to step 16

Step 16: print optimal size and location of DG

Step 17: stop

\section{TEST SYSTEM}

The proposed controllers are applied on two types of test systems:

Case 1: 6 bus system

Case 2: IEEE 33 bus system 


\section{RESULTS \& DISCUSSION}

\subsection{Case 1}

In case 1, the proposed method is tested on 6 bus system and is shown in fig. 2

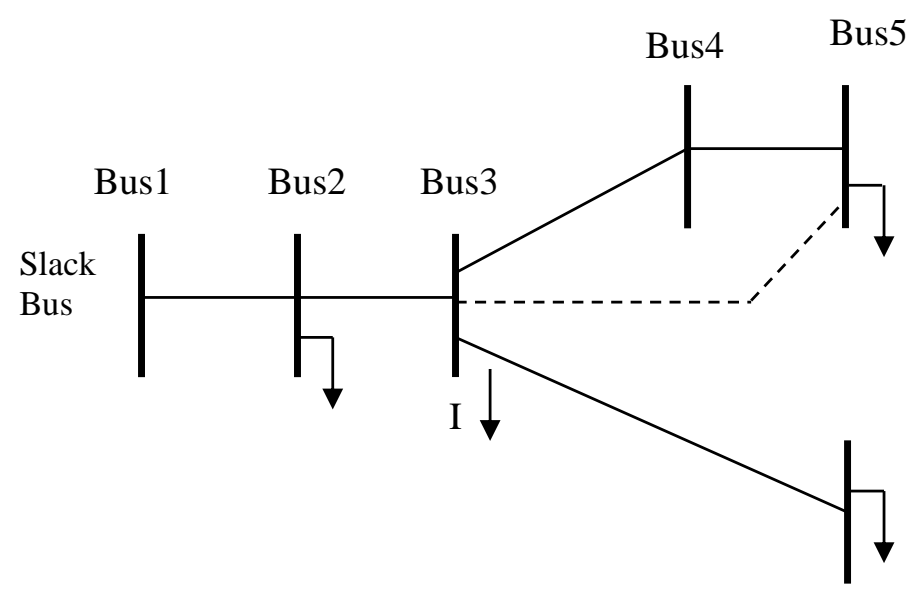

Figure 26 Bus Radial System.

Table 1 Optimal location of DG with proposed method

\begin{tabular}{cc}
\hline Method & Bus No \\
\hline MLI & 3 \\
\hline
\end{tabular}

Table 2 Power losses with respect to optimal size and location using proposed method

\begin{tabular}{cccccc}
\hline Method & $\begin{array}{c}\text { APL } \\
(\text { KW) }\end{array}$ & $\begin{array}{c}\text { RPL } \\
\text { (KVAR) }\end{array}$ & $\begin{array}{c}\text { Apparent } \\
\text { Power } \\
\text { (KVA) }\end{array}$ & $\begin{array}{c}\text { DG Size } \\
\text { (KW) }\end{array}$ & $\begin{array}{c}\text { DG } \\
\text { Location }\end{array}$ \\
\hline proposedMLI & 0.2607 & 0.147 & 0.2993 & 344 & 3 \\
\hline
\end{tabular}

Table 3 Power losses and minimum voltages without DG and with DG using proposed method

\begin{tabular}{ccccccc}
\hline Power Loss & Before DG & $\begin{array}{c}\text { After } \\
\text { DG }\end{array}$ & $\begin{array}{c}\% \\
\text { Decrease }\end{array}$ & Parameter & $\begin{array}{c}\text { Before } \\
\text { DG }\end{array}$ & $\begin{array}{c}\text { After } \\
\text { DG }\end{array}$ \\
\hline $\begin{array}{c}\text { Active Power } \\
\text { Loss (KW) }\end{array}$ & 0.6961 & 0.2607 & 67.8 & Vmin (p.u) & 0.997 & 0.999 \\
\hline $\begin{array}{c}\text { Reactive } \\
\begin{array}{c}\text { Power Loss } \\
\text { (KVAR) }\end{array}\end{array}$ & 0.362 & 0.147 & 66.5 & $\begin{array}{c}\text { VSI min } \\
\text { (p.u) }\end{array}$ & 0.989 & 0.996 \\
\hline $\begin{array}{c}\text { Apparent } \\
\text { Power Loss } \\
\text { (KVA) }\end{array}$ & 0.7838 & 0.2993 & 67.51 & & & \\
\hline
\end{tabular}

Table.1 shows the optimal locations of DG using proposed method (MLI).

Table. 2 shows the real, reactive and apparent power losses with proposed method MLI. Fig. 3 indicates the variation of power losses with respect to DG size using proposed method. 


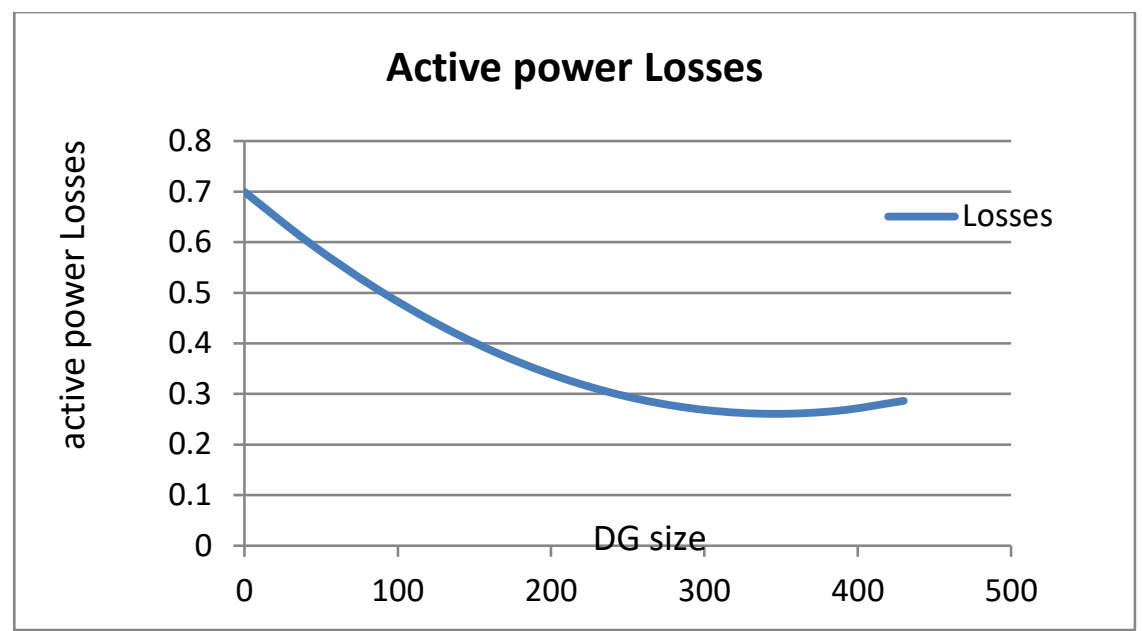

Figure 3 Active power losses with respect to DG size with proposed method.

Table 3 indicating how the active power, reactive and apparent power losses are decreasing with the proposed method. Minimum voltage and voltage stability index minimum values are also shown in table. 3.

From table 3, it is clear that the proposed method decreases active power by $67.8 \%$, reactive power by $66.5 \%$ and apparent power by $67.51 \%$.

From this discussion, it is clear that the proposed method is effectively decreasing power losses and increasing the voltages.

\subsection{Case 2}

Table 4 Optimal location of DG with different Existing methods

\begin{tabular}{lc}
\hline \multicolumn{1}{c}{ Method } & Bus No \\
\hline Analytical method & 6 \\
\hline Proposed MLI & 6 \\
\hline
\end{tabular}

Table 5 Power losses with respect to optimal size and location of DG using different existing methods with proposed method

\begin{tabular}{cccccc}
\hline Method & $\begin{array}{c}\text { APL } \\
(\text { KW })\end{array}$ & $\begin{array}{c}\text { RPL } \\
(\text { KVAR) }\end{array}$ & $\begin{array}{c}\text { Apparent } \\
\text { Power }(\text { KVA })\end{array}$ & $\begin{array}{c}\text { DG Size } \\
(\text { KW })\end{array}$ & $\begin{array}{c}\text { DG } \\
\text { Location }\end{array}$ \\
\hline Base Case & 202.34 & 134.9 & 243.21 & - & - \\
\hline $\begin{array}{c}\text { Analytical } \\
\text { method [5] }\end{array}$ & 111.1 & - & - & 2490 & 6 \\
\hline Proposed MLI & 104.19 & 74.81 & 128.27 & 2425 & 6 \\
\hline
\end{tabular}




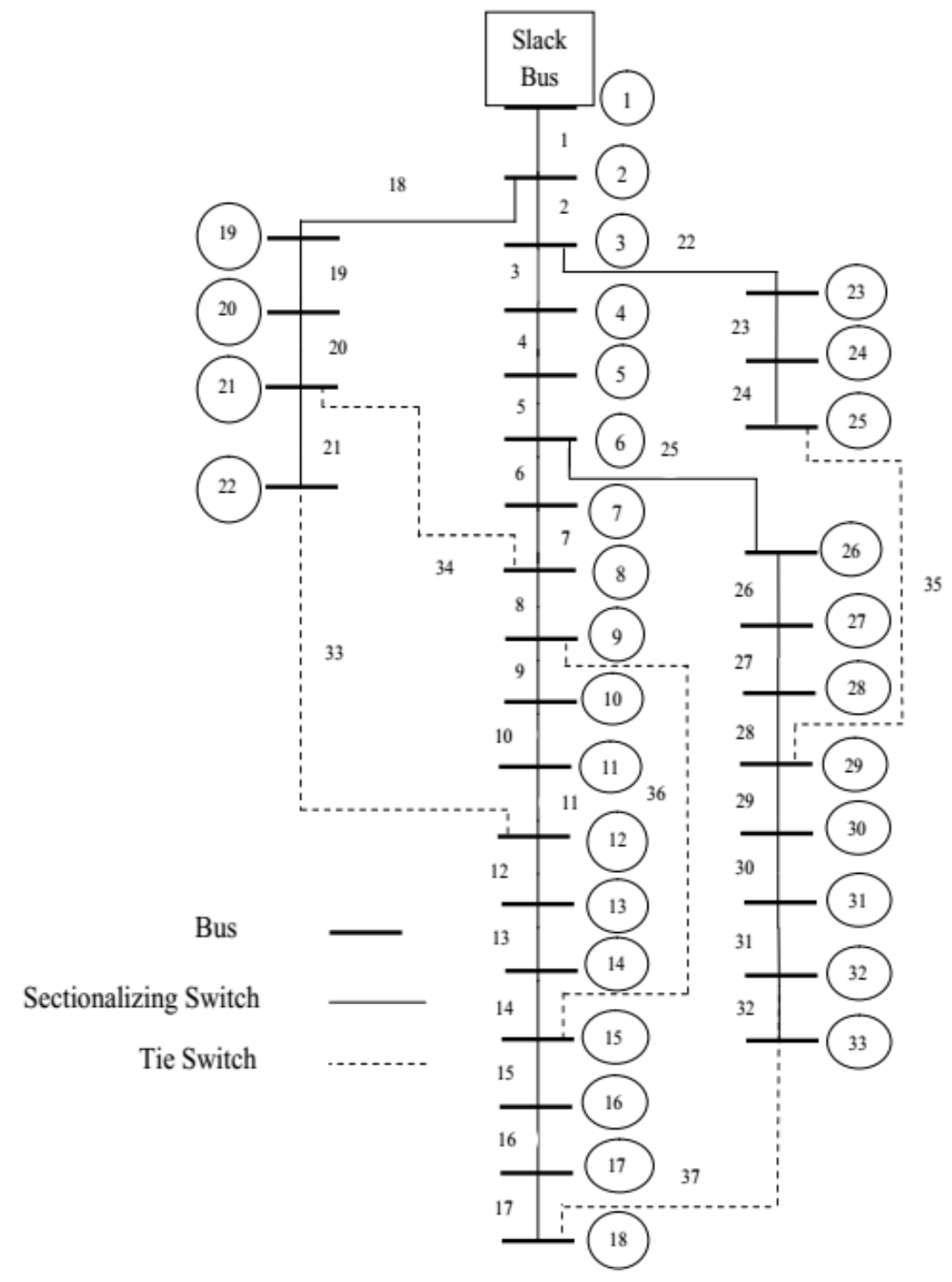

Figure 4 IEEE 33 bus radial system.

Table 6 Power losses and minimum voltages without DG and with DG using proposed method

\begin{tabular}{cccc}
\hline Power Loss & Before DG & After DG & \% Decrease \\
\hline Active Power Loss (KW) & 202.34 & 104.01 & 48.6 \\
\hline $\begin{array}{c}\text { Reactive Power Loss } \\
\text { (KVAR) }\end{array}$ & 134.9 & 74.81 & 44.62 \\
\hline $\begin{array}{c}\text { Apparent Power Loss } \\
\text { (KVA) }\end{array}$ & 243.19 & 128.05 & 47.1 \\
\hline
\end{tabular}

Table.4 shows the optimal locations of DG using Analytical method, and proposed method (MLI).

Table.5 shows how the real, reactive and apparent power losses are changing with respect to Analytical method, and proposed MLI. Fig.3 indicates the variation of power losses with respect to DG size using proposed method.

From table 6 , it is clear that the proposed method decreases active power by $48.6 \%$, reactive power by $44.62 \%$ and apparent power by $47.1 \%$. and other methods reactive and apparent losses are not discussed. 
The proposed method results compared with analytical method, from this real power losses reduced by $7 \mathrm{KW}$, size of DG is reduced by $0.11 \mathrm{MW}$, minimum voltage is improved by 0.27 p.u and $3.4 \%$ improvement in the loss reduction.

From this discussion, it is clear that the proposed method is effectively decreasing power losses and increasing the voltages.

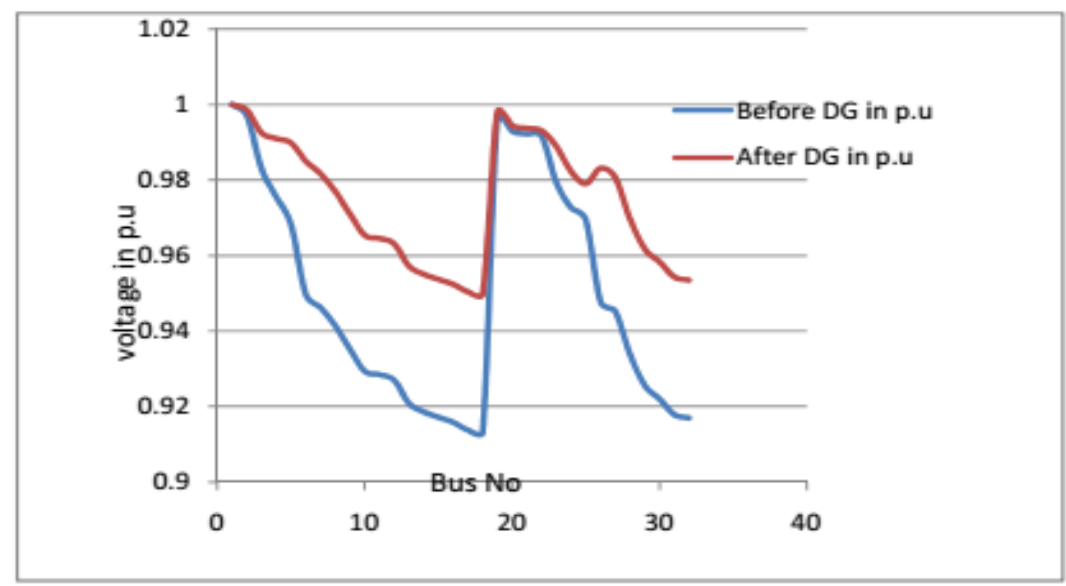

Figure 5 Voltage profile of IEEE 33 bus system.

Fig.5 shows the voltage profile of all the buses of IEEE 33 bus system, from this minimum voltage is improving using proposed method.

Active power loss, Reactive power loss and apparent power loss comparison is shown in fig.6. From this figure also, it can concluded that the proposed method is effective.

Table.8 indicates the power flows in the respective lines with and without DG considering MLI concept. Fig.8 shows the comparision, from this each line loading capability is increased with DG

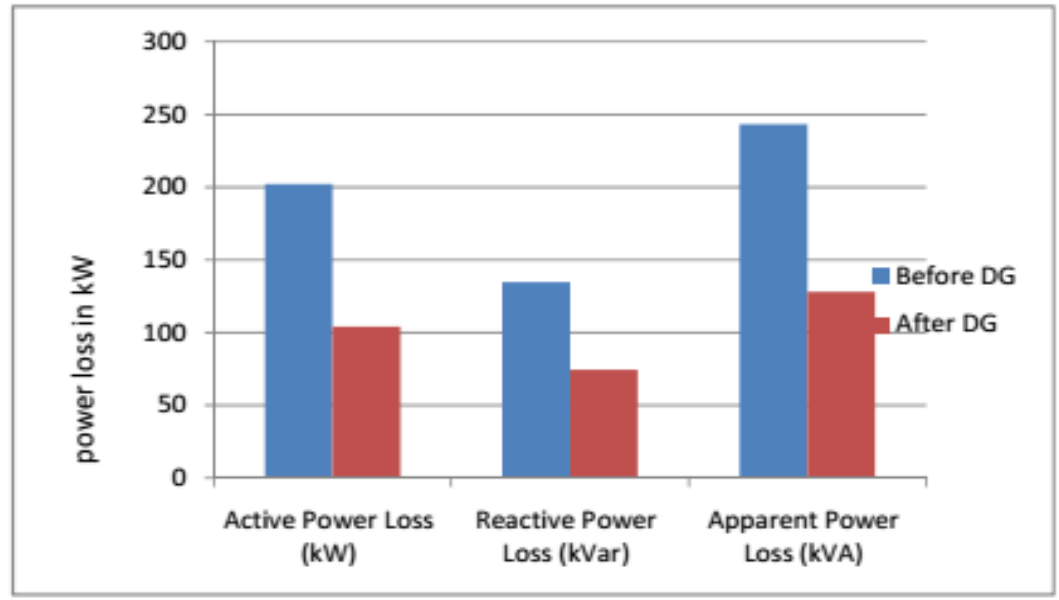

Figure 6 Power loss comparison without and with DG. 
MLI Technique for Placement and Sizing of DG for Minimum Line Losses

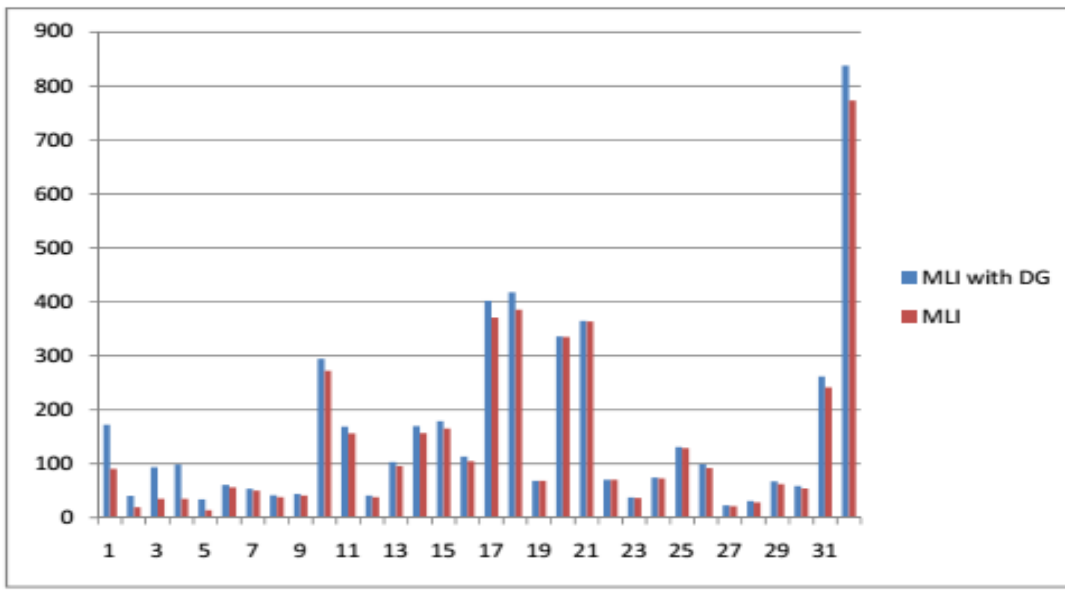

Figure 7 Power loss comparison without and with DG.

Table 7 maximum Loadability index with and without DG

\begin{tabular}{|c|c|c|}
\hline Line Num & MLI with DG & MLI \\
\hline 1 & 172.3629 & 90.5027 \\
\hline 2 & 40.2401 & 19.1683 \\
\hline 3 & 93.6783 & 34.5497 \\
\hline 4 & 98.9624 & 34.4941 \\
\hline 5 & 33.8381 & 13.7307 \\
\hline 6 & 60.5811 & 56.1957 \\
\hline 7 & 53.6314 & 49.7219 \\
\hline 8 & 41.0622 & 38.0398 \\
\hline 9 & 43.9639 & 40.6868 \\
\hline 10 & 294.1269 & 271.945 \\
\hline 11 & 168.6891 & 155.945 \\
\hline 12 & 40.9072 & 37.8074 \\
\hline 13 & 103.1655 & 95.2509 \\
\hline 14 & 169.5403 & 156.474 \\
\hline 15 & 179.0419 & 165.204 \\
\hline 16 & 113.1187 & 104.352 \\
\hline 17 & 402.0365 & 370.749 \\
\hline 18 & 417.9179 & 385.355 \\
\hline 19 & 68.3995 & 68.1871 \\
\hline 20 & 335.7889 & 334.739 \\
\hline 21 & 364.6503 & 363.508 \\
\hline 22 & 70.3875 & 70.1668 \\
\hline 23 & 37.2985 & 36.5568 \\
\hline 24 & 73.9895 & 72.4982 \\
\hline 25 & 131.0995 & 128.439 \\
\hline 26 & 99.3756 & 92.1539 \\
\hline 27 & 22.7979 & 21.1325 \\
\hline 28 & 30.9728 & 28.6576 \\
\hline 29 & 67.2286 & 62.1195 \\
\hline 30 & 58.7839 & 54.2845 \\
\hline 31 & 261.683 & 241.485 \\
\hline 32 & 838.0165 & 773.214 \\
\hline
\end{tabular}




\section{CONCLUSION}

In this paper, Maximum loadability index method is proposed for optimal location and sizing of DG. This MLI method is implemented on IEEE 6 bus system and IEEE 33 Bus systems. The performance of MLI is compared with previous existing methods and concluded that MLI method enhancing the loading capabilities of the lines, voltages at buses, decreasing the real, reactive and apparent power losses effectively.

\section{REFERENCES}

[1] J Griffin, K. Tomsovic, D. Secrest, and A.Law, (2000) "Placement of dispersed generation systems for reduced losses," in Proc. 33rd Annu. Hawaii Int.Conf.System Science, Maui, HI.

[2] Wang C, Nehrir MH. (2004) Analytical approaches for optimal placement of distributed generation sources in power system. IEEE Trans PWRS, 19(4):2068-76.

[3] T. K. A. Rahman, S. R. A. Rahim, and I. Musirin. (2004) Optimal allocation and sizing of embedded generators. Proceedings of Power and Energy Conference. PECon, pp. $288-$ 294.

[4] Naderi E, (2004) A dynamic approach for distribution system planning considering distributed generation. IEEE Trans Power Syst; 26:307-14.

[5] Acharya N, Mahat P, Mithulananthan N. (2006) An analytical approach for DG allocation in primary distribution network. Int J Electr Power; 28(10): 669-78.

[6] A.Alsaadi, B.Gholami, (2009)"An Effective Approach for Distribution System Power Flow Solution",Int J Elec. and Comp Engg,vol 3,No 1, pp. 143-157

[7] S.Sunisith,K.Meena, (2014)"Backward/Forward Sweep Based Distribution Load Flow Method", Int J Elec Engg,Vol 5,No 9, pp. 1539-1544.

[8] A. Keane et al. (2013) "State-of-the-Art Techniques and Challenges Ahead for Distributed Generation Planning and Optimization," IEEE Trans. Power Systems, vol. 28, no. 2, pp.1493-1502.

[9] A. Alarcon-Rodriguez, G. Ault, S. Galloway, (2010) "Multi-objective planning of distributed energy resources: A review of the state-of-the-art," Renewable and Sustainable Energy Reviews, vol. 14, pp. 1353-1366, Renewable and Sustainable Energy Reviews 14, 1353-1366.

[10] C.L.T. Borges and D.M. Falcao, (2006) "Optimal distributed generation allocation for reliability, losses and voltage improvement," International journal of power and energy systems, vol.28.no.6, pp.413-420, July

[11] G. Celli, E. Ghiani, S. Mocci, F. Pilo, (2005) "A multi-objective evolutionary algorithm for the sizing and siting of distributed generation," IEEE Trans. Power Systems, vol. 20, no. 2, pp. $750-757$.

[12] B Venkatesh, Rakesh Ranjan and H B Gooi, (2004) "Optimal reconfiguration of radial distribution system to maximize loadability", IEEE Transactions on Power Systems, Vol 19, no.1, pp.260-266. 